\title{
Uji Kekerasan Functionally Graded Materials Berbasis Aluminium Titanat dengan Penstabil MgO
}

\begin{tabular}{l}
\hline Received \\
6 April 2017 \\
Revised \\
30 April 2018 \\
Accepted for Publication \\
02 Agusutus 2018 \\
Published \\
30 Agustus 2018 \\
\hline
\end{tabular}

This work is licensed under a Creative under a Creative Commons Attributi ShareAlike 4.0 International License.

\author{
A S Fauzi ${ }^{1 *}$, H Istiqlaliyah ${ }^{1}, S$ Pratapa $^{2}$ \\ 1. Program Studi Teknik Mesin, Fakultas Teknik, Universitas Nusantara PGRI Kediri, Kediri 64112, \\ Indonesia \\ 2. Jurusan Fisika, FMIPA, Institut Teknologi Sepuluh Nopember Surabaya, Surabaya 60111, Indonesia \\ *Email: $\underline{\text { sulhanfauzi@ unpkediri.ac.id }}$
}

\begin{abstract}
This research was conducted to find out the hardness characteristic of functionally graded materials based on aluminium titanat and stabilized by magnesium oxide (FGMs-ATM) made by recurrent infiltration method. The hardness test was conducted in uniaxial direction to compare hardness value of sample with load variation from 0.2 until $1 \mathrm{~N}$. To form FGMsATMs, the samples were sintered at $1550{ }^{\circ} \mathrm{C}$, as comparable were the sintered FGMs at a temperature of $1450{ }^{\circ} \mathrm{C}$. The hardness analysis result with Vickers Hardness test showed hardness value of FGMs-ATM fluctuative to variation of load between $0.2 \mathrm{~N}$ to $1 \mathrm{~N}$, that is $64.55 \mathrm{HV}$ at the lowest loading $0.5 \mathrm{~N}$ and highest $118.6 \mathrm{HV}$ at highest loading $1 \mathrm{~N}$. The fluctuation of the hardness value to the given load variation shows the FGMs-ATM sample approaching brittle properties. While the increasing in sinter temperature further decreases the brittleness.
\end{abstract}

Keywords: FGMs-ATM, infiltration, sinter, density, hardness

\begin{abstract}
Abstrak
Penelitian ini dilakukan untuk mengetahui karakteristik kekerasan functionally graded materials berbasis aluminium titanat yang distabilisasi magnesium oksida (FGMs-ATM) yang telah dibuat dengan metode infiltrasi berulang. Uji kekerasan dilakukan pada arah uniaksial untuk membandingkan nilai kekerasan sampel dengan variasi beban 0,2 sampai 1 N. Untuk membentuk FGMs-ATM, sampel disinter pada temperatur $1550{ }^{\circ} \mathrm{C}$, sebagai pembanding adalah FGMs-ATM yang disinter pada temperatur $1450{ }^{\circ} \mathrm{C}$. Hasil analisis sifat kekerasan dengan uji Vickers Hardness menunjukkan nilai kekerasan FGMs-ATM yang fluktuatif terhadap variasi beban antara $0,2 \mathrm{~N}$ sampai dengan $1 \mathrm{~N}$, yaitu $64,55 \mathrm{HV}$ pada pembebanan terendah $0,5 \mathrm{~N}$ dan tertinggi $118,6 \mathrm{HV}$ pada pembebanan tertinggi $1 \mathrm{~N}$. Fluktuasi nilai kekerasan terhadap variasi beban yang diberikan menunjukkan sampel FGMs-ATM mendekati sifat getas/ rapuh (brittle). Sedangkan peningkatan temperatur sinter semakin menurunkan sifat getasnya.
\end{abstract}

Kata Kunci: FGMs-ATM, infiltrasi, sinter, densitas, kekerasan

\section{Pendahulan}

Functionally graded materials merupakan bahan komposit yang terdiri dari dua komponen material dan memiliki perubahan komposisi secara gradual dari komponen satu ke komponen yang lainnya [1]. FGMs memiliki mikrostruktur dan sifat dengan perubahan secara kontinyu di seluruh material yang diharapkan memiliki low residual dan thermal stresses serta dapat meningkatkan kekuatan ikatan antara material yang berbeda [2]. Mikrostruktur FGMs bervariasi secara spasial melalui distribusi dari fase penguatan yang tidak seragam, dengan menggunakan penguatan yang memiliki perbedaan sifat, ukuran dan bentuk, serta dengan saling bertukar antara fase penguatan dan matriks secara kontinyu. Salah satu metode yang digunakan untuk melakukan sintesis pada bahan FGMs adalah dengan menggunakan teknik infiltrasi cairan [3]. Metode infiltrasi ini relatif mudah dan efisien karena 
memanfaatkan material berpori sebagai matriks yang dicelupkan kedalam cairan infiltran yang akan mengisi pori dari material tersebut sebagai filernya.

Berbagai penelitian telah dilakukan dalam pembuatan FGMs, diantaranya sintesis $\mathrm{FGMs} \mathrm{Al}_{2} \mathrm{O}_{3^{-}}$ $\mathrm{Al}_{2} \mathrm{TiO}_{5}$ (AT) tanpa penstabil [5], $\mathrm{Al}_{2} \mathrm{O}_{3}-\mathrm{AT} \mathrm{ZrO}_{2}$ dengan $\mathrm{ZrO}_{2}$ sebagai penstabil [6], sintesis $\mathrm{FGMs}$ berbasis AT dengan penstabil MgO [7]. Penelitian pembuatan FGMs menggunakan penambahan $\mathrm{MgO}$, menyebabkan turunnya nilai kekerasan FGMs A/AT-MgO baik secara uniaksial maupun tampang lintang [8]. Selain itu juga telah dilakukan penelitian tentang mikrostruktur dan dekomposisi dari FGMs alumunium titanat-corundum dengan penambahan periclas [9].

Aluminium titanat $\left(\mathrm{Al}_{2} \mathrm{TiO}_{5}\right)$ mendorong berbagai aplikasi karena sifat fisisnya yang sangat unik. Diantara sifat fisis tersebut adalah ketahanan thermal shock yang sangat baik karena memiliki koefisien ekspansi termal yang relatif rendah $\left(\sim 1 \times 10^{-6}{ }^{\circ} \mathrm{C}^{-1}\right)$ dan titik lebur yang tinggi $\left(1860{ }^{\circ} \mathrm{C}\right)$. Sifat termal ini membuat $\mathrm{Al}_{2} \mathrm{TiO}_{5}$ sangat sesuai untuk aplikasi pada temperatur tinggi, selain itu sifat thermal shock resistance dan thermal insulation dari $\mathrm{Al}_{2} \mathrm{TiO}_{5}$ juga dibutuhkan, seperti pada komponen untuk internal combustion engines, exhaust port liners, metallurgy, and thermal barriers [4].

Aplikasi aluminium titanat memerlukan karaterisasi fisis yang kompleks lebih dari sifat termalnya misalnya karakteristik mekanik bahan. Lengkapnya penguasan karakteristik fisis dari suatu bahan menjamin kemapanan aplikasi bahan tersebut. Dengan demikian urgen melakukan penelitian untuk mengetahui karakter mekanik, yaitu nilai kekerasan dari keramik FGMs berbahan dasar alumina transisi prakeramik. Urgensi kararterisasi mekanik diperkuat dengan keberadaan penstabil MgO. Aluminium titanat dengan penstabil $\mathrm{MgO}$ merupakan hasil infiltrasi berulang yang disinter pada temperatur $1550{ }^{\circ} \mathrm{C}$. Sebagai pembanding adalah nilai kekerasan sampel yang dilakukan pada tempertur $1450{ }^{\circ} \mathrm{C}$. Pengamatan yang akan dilakukan adalah uji kekerasan menggunakan vickers hardness tester dengan variasi beban.

\section{Metode Penelitian}

\subsection{Persiapan Bahan Uji}

Pembuatan FGMs corundum infiltrasi dengan penstabil MgO (FGMs ATM) adalah dengan kompaksi serbuk alumina transisi prakeramik yang telah dicampur dengan serbuk $\mathrm{MgO}$ dengan perbandingan $2 \% \mathrm{MgO}$ dari berat seluruh sampel, pada tekanan 8000 pound, sehingga serbuk menjadi pelet berbentuk silinder dengan diameter $11,3 \mathrm{~mm}$ dan tinggi $3,1 \mathrm{~mm}$. Kemudian diprasinter pada temperatur $1200{ }^{\circ} \mathrm{C}$ selama 1 jam supaya sampel lebih padat dan tidak rapuh serta menghilangkan zinc stearat yang tercampur saat kompaksi.

Setelah prasinter, selanjutnya adalah pengujian porositas terhadap sampel dengan metode archimedes. Pengujian porositas dilakukan untuk mendapatkan sampel dengan nilai porositas yang terkontrol (dalam range yang berdekatan). Langkah selanjutnya adalah inflitrasi dengan larutan infiltran $\mathrm{TiCl}_{3}(15 \%)$ dengan pengulangan sebanyak 5 kali. Metode infiltrasi dilakukan dengan mencelupkan sampel prakeramik ke dalam laruran $\mathrm{TiCl}_{3} 20 \%$ selama 30 menit. Kemudian sampel dikeringkan dengan menggunakan lampu dengan temperatur sekitar $80{ }^{\circ} \mathrm{C}$ hingga sampel kering, dan dilakukan pengulangan sebanyak 5 kali pengulangan. Massa sampel ditimbang setiap sebelum dan sesudah proses infiltrasi untuk mengetahui banyaknya infiltran yang masuk melalui perubahan massa yang terjadi.

Setelah itu sampel disinter pada temperatur $1200{ }^{\circ} \mathrm{C}$ selama 2 jam hingga terbentuk fasa corundum-rutile, selanjutnya sampel disinter kembali pada temperatur tinggi yaitu pada temperatur $1550{ }^{\circ} \mathrm{C}$ selama 3 jam. Kemudian dilakukan pemolesan dan pemotongan bahan uji. Pemolesan dilakukan dalam beberapa tahapan, tahapan pertama, grinding (pemolesan) dengan amplas/ kertas gosok ukuran 800 dan 1000, kedua pemolesan halus dengan amplas ukuran 1200, 1500 kemudian 2000.

\subsection{Karakterisasi FGMs AT-MgO}

Karakterisasi sifat fisik dari sampel keramik FGMs AT-MgO yang diamati dalam penelitian ini meliputi perubahan massa, volume, densitas dan porositas. Uji mekanik dilakukan dengan vickers hardness tester untuk mengetahui nilai kekerasan vickers sehingga dapat diketahui sifat mekanik bahan. Uji kekerasan dilakukan pada arah uniaksial seperti Gambar 1 dengan beban yang bervariasi yaitu 0,$2 ; 0,3 ; 0,5 ; 0,9$ dan $1 \mathrm{~N}$ pada permukaan sampel. 


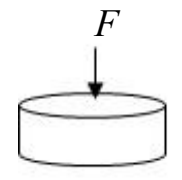

Gambar 1. Uji Kekerasal Uniaksial

Dalam penelitian ini nilai kekerasan diperoleh dari uji sampel dengan menggunakan alat Mikro Vickers Hardness Testing Machine yang menggunakan dasar persamaan:

$$
H_{v}=1,85544 \frac{F}{d^{2}},
$$

dengan $H_{\mathrm{v}}$ merupakan kekerasan vickers, $F$ merupakan gaya tekan, dan $d$ merupakan diagonal indentor.

\section{Hasil dan Pembahasan}

\subsection{Sifat Fisik}

Sampel FGMs yang telah disinter pada temperatur $1550{ }^{\circ} \mathrm{C}$ dengan holding time selama 3 jam memiliki wujud fisik yang cenderung sama dengan sampel yang disinter pada temperatur $1450{ }^{\circ} \mathrm{C}$, yaitu permukaan atasnya menjadi cembung. Hal ini menunjukkan kegradualan komposisi komposit yang merupakan salah satu sifat FGMs sehingga diperoleh sifat fisik yang berubah terhadap kedalaman [5], akibat larutan $\mathrm{TiCl}_{3}$ yang terinfiltrasi mengisi pori-pori bagian atas sampel dengan komposisi yang bertingkat (gradual), sehingga setelah dipanaskan pada temperatur tinggi (sinter) mengalami perbedaan dalam pemuaian maupun penyusutannya.

Hasil penentuan porositas, densitas dan penyusutan volume ditunjukkan pada Tabel 1. Berdasarkan Tabel 1 diketahui nilai densitasnya mengalami kenaikan setelah sinter sedang porositasnya mengalami penurunan nilai setelah sinter. Nilai perubahan densitas dan porositas tersebut sama seperti sampel yang disinter pada temperatur $1450{ }^{\circ} \mathrm{C}$. Besaran $\Delta m_{l}$ adalah perubahan massa sebelum dan setelah infiltrasi, $\Delta m_{2}$ perubahan massa sebelum dan setelah sinter, $P o$ adalah porositas sebelum sinter, $D o$ adalah densitas sebelum sinter, $P i$ adalah porositas setelah sinter, $D i$ adalah densitas setelah sinter, $S$ adalah penyusutan volume setelah sinter.

Nilai densitas sampel FGMs ATM mengalami kenaikan setelah proses sinter. Sedang nilai porositas FGMs ATM mengalami penurunan setelah proses sintering. Hal ini akibat dari penambahan aditif $\mathrm{MgO}$ menyebabkan terjadinya substitusi $\mathrm{Mg}$ yang menyusutkan pori-pori AT dikarenakan jarijari ion $\mathrm{Mg}^{2+}(0,086 \mathrm{~nm})$ lebih besar daripada $\mathrm{Al}^{3+}(0,068 \mathrm{~nm})$ dan $\mathrm{Ti}^{4+}(0,075 \mathrm{~nm})$ sehingga menyebabkan jarak antar butir $\mathrm{Al}_{2} \mathrm{O}_{3}$ dan $\mathrm{TiO}_{2}$ semakin dekat. Perbedaan temperatur sinter juga cenderung memperbesar perbedaan porositas dan densitas sampel yang ditunjukkan dengan nilai prosentase penyusutan volume yang semakin besar seiring dengan kenaikan temperatur sinter.

Tabel 1. Perubahan massa, densitas, porositas dan penyusutan volume pada temperatur sinter $1550{ }^{\circ} \mathrm{C}$

\begin{tabular}{ccccccc}
\hline$\Delta \boldsymbol{m}_{1}(\mathbf{\%})$ & $\Delta \boldsymbol{m}_{2}(\mathbf{\%})$ & $\begin{array}{c}\boldsymbol{P}_{\boldsymbol{o}} \\
\left(\mathrm{gr} / \mathrm{cm}^{3}\right)\end{array}$ & $\begin{array}{c}\boldsymbol{D}_{\boldsymbol{o}} \\
\left(\mathrm{gr} / \mathrm{cm}^{3}\right)\end{array}$ & $\begin{array}{c}\boldsymbol{P}_{\boldsymbol{i}} \\
\left(\mathrm{gr} / \mathrm{cm}^{3}\right)\end{array}$ & $\begin{array}{c}\boldsymbol{D}_{\boldsymbol{i}} \\
\left(\mathrm{gr} / \mathrm{cm}^{3}\right)\end{array}$ & $\boldsymbol{S}(\%)$ \\
\hline 18,08 & 1,12 & 58,76 & 3,33 & 5,20 & 3,35 & 49,54 \\
\hline
\end{tabular}

Tabel 2. Perubahan massa, densitas, porositas dan penyusutan volume pada temperatur sinter $1450{ }^{\circ} \mathrm{C}[9]$

\begin{tabular}{ccccccc}
\hline$\Delta \boldsymbol{m}_{1}(\%)$ & $\Delta \boldsymbol{m}_{2}(\mathbf{\%})$ & $\begin{array}{c}\boldsymbol{P}_{\boldsymbol{o}} \\
\left(\mathrm{gr} / \mathrm{cm}^{3}\right)\end{array}$ & $\begin{array}{c}\boldsymbol{D}_{\boldsymbol{o}} \\
\left(\mathrm{gr} / \mathrm{cm}^{3}\right)\end{array}$ & $\begin{array}{c}\boldsymbol{P}_{\boldsymbol{i}} \\
\left(\mathrm{gr} / \mathrm{cm}^{3}\right)\end{array}$ & $\begin{array}{c}\boldsymbol{D}_{\boldsymbol{i}} \\
\left(\mathrm{gr} / \mathrm{cm}^{3}\right)\end{array}$ & $\boldsymbol{S}(\%)$ \\
\hline 17,91 & 5,20 & 59,23 & 3,34 & 21,25 & 3,41 & 38,46 \\
\hline
\end{tabular}




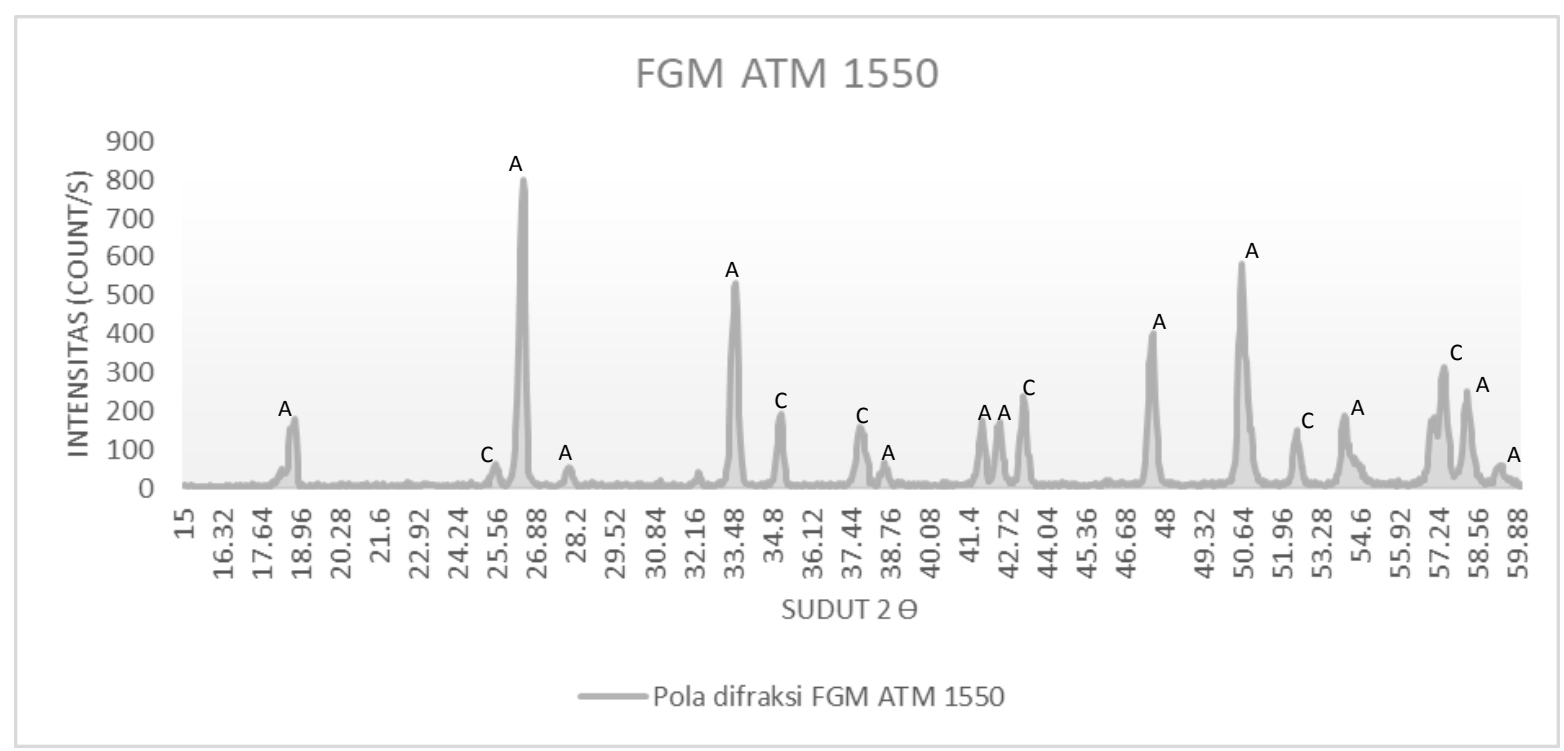

Gambar 2. Pola-pola difraksi sampel FGM ATM pada temperatur sinter $1550{ }^{\circ} \mathrm{C}$ Keterangan: $\mathrm{A}=\mathrm{AT}, \mathrm{C}=$ Korundum

\subsection{Identifikasi Fasa}

Untuk mengetahui fasa-fasa yang terkandung di dalam sampel dilakukan analisis kualitatif menggunakan hasil pola difraksi Sinar-X dengan software X'Pert Graphics and Identify. Dari hasil analisis search match dengan basis data diketahui bahwa posisi-posisi puncak difraksi terukur pada sampel FGMs ATM. Pada sampel FGMs ATM yang disinter pada temperatur $1550{ }^{\circ} \mathrm{C}$ dan terdapat fasa AT sesuai dengan data PDF 09-0252. Pola hasil difraksi Sinar-X untuk sampel FGM ATM dapat dilihat pada Gambar 2.

Dari pola difraksi Sinar-X pada Gambar 2 terlihat bahwa intensitas puncaknya mengalami perubahan, terlihat bahwa kandungan AT meningkat seiring bertambahnya temperatur sinter. Intensitas tertinggi pola difraksi untuk AT pada sampel dengan temperatur sinter $1550{ }^{\circ} \mathrm{C}$ terjadi pada sudut $26,44^{\circ}$ sebesar $801 \mathrm{count} / \mathrm{s}$, sedang pada sampel dengan temperatur sinter $1450{ }^{\circ} \mathrm{C}$ pada sudut yang hampir sama yaitu 26,46 mempunyai intensitas 729 count/s.

\subsection{Sifat Mekanik}

Uji kekerasan dilakukan pada tampang uniaksial dengan menggunakan beban yang bervariasi, yaitu 0,2; 0,3; 0,5; 0,9 dan $1 \mathrm{~N}$. Hasil uji kekerasan dari alat Mikro Vickers Hardness Testing Machine dapat dilihat di Gambar 3.

Hasil perhitungan dengan persaman (1) diperoleh nilai kekerasan vickers 64,55 HV pada pembebanan $0,2 \mathrm{~N}$, pembebanan $0,3 \mathrm{~N}$ mengalami kenaikan menjadi 83,15 HV. Pada pembebanan 0,5 $\mathrm{N}$ menjadi 103,7 HV. Untuk pembebanan selanjutnya, $0,9 \mathrm{~N}$ dan $1 \mathrm{~N}$, nilai kekerasan vickers juga mengalami kenaikan yaitu, menjadi 132,83 HV dan 118,6 HV. Perubahan nilai kekerasan vickers untuk temperatur sinter $1550{ }^{\circ} \mathrm{C}$ secara keseluruhan diperlihatkan pada Gambar 4. Sebagai perbandingan juga diperlihatkan nilai perubahan kekerasan vickers pada temperatur sinter $1450{ }^{\circ} \mathrm{C}$ pada Gambar 5.

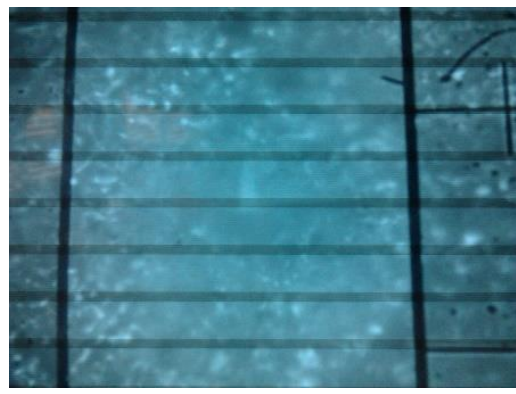

Gambar 3. Hasil indentasi Mikro Vickers Hardness Testing Machine 


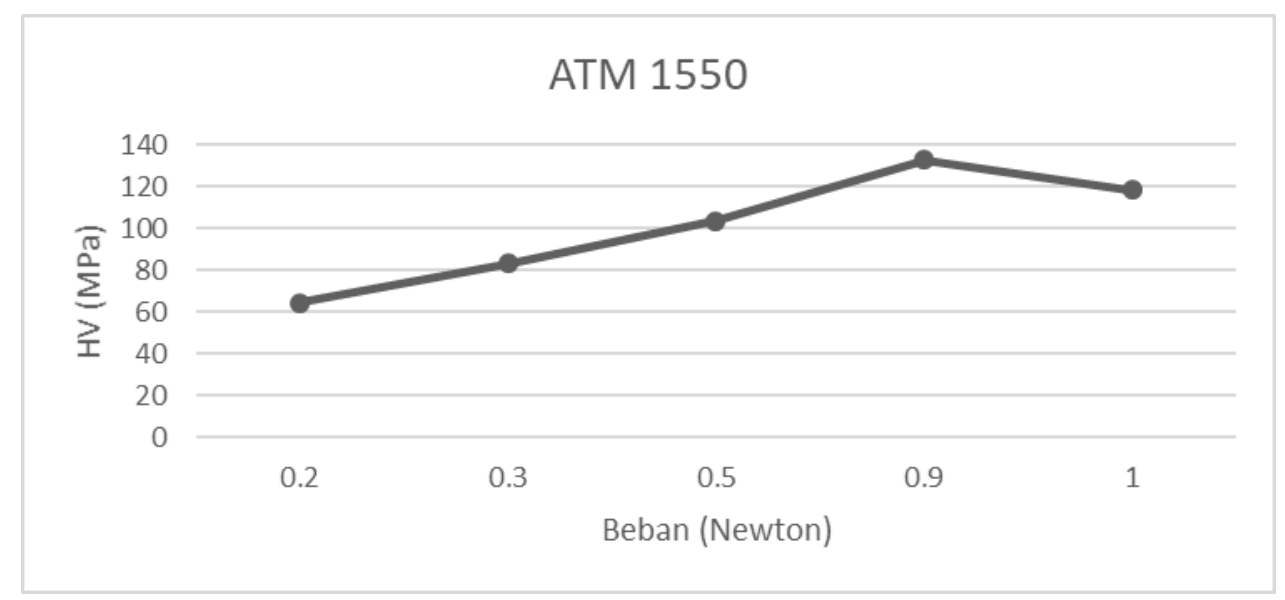

Gambar 4. Nilai kekerasan Vickers FGMs AT-MgO untuk temperatur sinter $1550{ }^{\circ} \mathrm{C}$

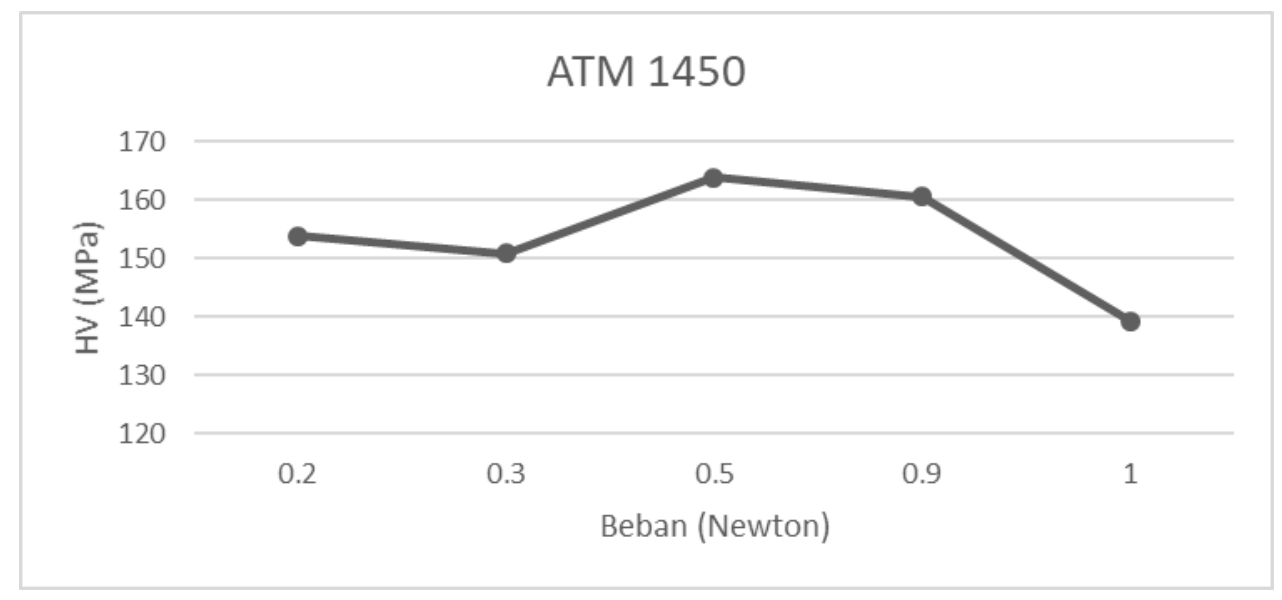

Gambar 5. Nilai kekerasan Vickers FGMs ATM untuk temperatur sinter $1450{ }^{\circ} \mathrm{C}[10]$

Pada Gambar 4 dan 5, terlihat bahwa sampel FGMs ATM memiliki nilai kekerasan vickers yang bervariasi terhadap variasi beban yang diberikan dan temperatur sinternya. Nilai kekerasan vickers tertinggi didapat pada temperatur sinter $1450{ }^{\circ} \mathrm{C}$, yaitu $163,74 \mathrm{HV}$ pada pembebanan $0,5 \mathrm{~N}$ dan nilai kekerasan vickers terendahnya adalah $64,5 \mathrm{HV}$ pada pembebanan $0,5 \mathrm{~N}$ untuk temperatur sinter 1550 ${ }^{\circ} \mathrm{C}$. Secara umum kekerasan vickers sampel FGMs ATM tidak begitu terpengaruh oleh variasi beban yang diberikan, hal ini ditunjukkan dari nilai perubahan nilai kekerasan vickers yang bervariasi akibat perbedaan beban yang diberikan baik untuk tempetarur sinter $1550{ }^{\circ} \mathrm{C}$ maupun $1450{ }^{\circ} \mathrm{C}$. Sedangkan peningkatan temperatur, yaitu dari $1450{ }^{\circ} \mathrm{C}$ ke $1550{ }^{\circ} \mathrm{C}$ semakin menurunkan nilai kekerasan FGMs ATM. Hal ini menunjukkan penambahan temperatur sinter cenderung mendekati sifat elastis (ductile) atau semakin menurunkan sifat kerapuhannya (brittle). Variasi nilai kekerasan juga terjadi karena ketidaksempurnaan dalam proses peleburan dan pengecoran, dimana partikel silikon karbida sangat sulit bercampur secara merata dengan aluminium dan alumina, serta timbulnya cacat porositas (void) akibat dari masih terdapatnya udara yang terperangkap di dalam material yang tidak sepenuhnya terbuang pada saat proses degassing [11].

\section{Kesimpulan}

Nilai rata-rata kekerasan vickers sampel FGMs ATM yang disinter pada temperatur $1550{ }^{\circ} \mathrm{C}$ lebih rendah jika dibandingkan dengan sampel FGM ATM yang disinter pada temperatur $1450{ }^{\circ} \mathrm{C}$, yaitu $100,56 \mathrm{HV}$ pada temperatur $1550{ }^{\circ} \mathrm{C}$ dan $153,74 \mathrm{HV}$ pada temperatur $1450{ }^{\circ} \mathrm{C}$. Variasi beban yang 
diberikan tidak begitu memengaruhi nilai kekerasan vickers, hal ini menunjukkan bahwa sampel FGM ATM dengan temperatur sinter $1550^{\circ} \mathrm{C}$ semakin menurunkan sifat brittle FGMs ATM.

\section{Daftar Rujukan}

[1] A. J. Ruys, E. B. Popov, D. Sun, J. J. Russell, and C. C. J. Murray, "Functionally graded electrical/thermal ceramic systems," J. Eur. Ceram. Soc., vol. 21, no. 10-11, pp. 2025-2029, 2001.

[2] G. Jin, M. Takeuchi, S. Honda, T. Nishikawa, and H. Awaji, "Properties of multilayered mullite/Mo functionally graded materials fabricated by powder metallurgy processing," Mater. Chem. Phys., vol. 89, no. 2-3, pp. 238-243, 2005.

[3] S. Pratapa, "Synthesis and Character of a Functionally-graded Aluminium Titanate/zirconiaalumina Composite," Curtin University, 1997.

[4] R. D. Skala, D. Li, and I. M. Low, "Diffraction, structure and phase stability studies on aluminium titanate," J. Eur. Ceram. Soc., vol. 29, no. 1, pp. 67-75, 2009.

[5] S. Pratapa and I. M. Low, "Synthesis and properties of functionally-gradient aluminium titanate mullite-ZTA composites," J. Mater. Sci. Lett., vol. 15, no. 9, pp. 800-802, 1996.

[6] S. Pratapa and I. M. Low, "Infiltration-processed, functionally graded aluminium titanate/zirconia-alumina compositePart II Mechanical properties," J. Mater. Sci., vol. 33, no. 12, pp. 3047-3053, 1998.

[7] K. Umaroh, "Sintesis FGMs $\alpha$ - Al2O3/Al2TiO5 Distabilisasi MgO dengan Metode Infiltrasi Berulang," Institut Teknologi Sepuluh Nopember Surabaya, 2010.

[8] E. Weddakarti, "No TitleKarakterisasi Mikrostruktur dan Kekerasan FGMs $\alpha$-Al2O3/Al2TiO5Distabilisasi-MgO Hasil Infiltrasi Berulang," Institut Teknologi Sepuluh Nopember Surabaya, 2011.

[9] S. Pratapa, K. Umaroh, and E. Weddakarti, "Microstructural and decomposition rate studies of periclase-added aluminum titanate-corundum functionally-graded materials," Mater. Lett., vol. 65, no. 5, pp. 854-856, 2011.

[10] A. S. Fauzi, S. Pratapa, and M. H. E. Santoso, "SINTESIS BAHAN UBAHAN GRADUAL ALUMINUM TITANAT/KORUNDUM DARI ALUMINA TRANSISI DENGAN PENAMBAHAN MgO,” J. Mat. Sains dan Teknol., vol. 13, no. 2, pp. 80-86, 2012.

[11] H. Sukma, R. Prasetyani, D. Rahmalina, and R. Imanuddin, "Peran penguat partikel alumina dan silikon karbida terhadap kekerasan material komposit matriks aluminium," Pros. Semnastek, 2015. 